\title{
Southern Highland Craft Guild
}

By: Anna Craft

Craft, A. (June 01, 2011). Southern Highland Craft Guild. Serials Review, 37, 2, 120-122.

http://dx.doi.org/10.1016/j.serrev.2011.02.003

Made available courtesy of Elsevier: http://www.elsevier.com

\begin{abstract}
*** Reprinted with permission. No further reproduction is authorized without written permission from Elsevier. This version of the document is not the version of record. Figures and/or pictures may be missing from this format of the document.
\end{abstract}

\begin{abstract}
:
The collections of the Southern Highland Craft Guild are available to visitors at the Folk Art Center on the Blue Ridge Parkway in Asheville, North Carolina. Here visitors can explore library and archival materials that document traditional and contemporary arts and crafts, as well as southern Appalachian history and culture. The educational experience is enhanced through the Folk Art Center's rotating gallery exhibits, crafting demonstrations, and other educational and outreach events. Serials Review visits the center to learn about the library's history, collections, procedures, and initiatives.
\end{abstract}

Keywords: Folk Art Center | North Carolina | archives | arts and crafts | Appalachian history | Appalachian culture | library collections

\section{Articles:}

Introduction

Travelers on the Blue Ridge Parkway will find the Folk Art Center at milepost 382 in Asheville, North Carolina. The rustic but airy and bright building is home to the Southern Highland Craft Guild and houses the guild's library and archives, three galleries, spaces for craft demonstrations and special events, and Allanstand Craft Shop, which sells the wares of guild members. A Blue Ridge Parkway information desk and an Eastern National bookstore are also located here. The center serves as a showcase for traditional and contemporary crafts, all within the context of the southern Appalachian region. Visitors can enjoy the picturesque scenery of the surrounding Appalachian Mountains from the picnic tables around the Folk Art Center or by taking a brief jaunt on the Mountains to Sea Trail, which crosses the entrance road to the center. Other nearby 
parkway attractions include Craggy Gardens and Mount Pisgah. The greater Asheville area offers a wealth of cultural and recreational institutions and opportunities, such as the North Carolina Arboretum and the Biltmore Estate.

\section{History}

The Southern Highland Craft Guild, which was originally chartered in 1930 as the Southern Mountain Handicraft Guild and later the Southern Highland Handicraft Guild, was created with a mission to foster and encourage the production of handmade crafts in the southern Appalachian region, to market these craft items, and to educate the public about traditional crafts and crafting. Today the organization represents over nine hundred craftspeople in 293 counties of nine southeastern states. The counties together comprise the southern Appalachian Mountains, and the states represented are Alabama, Georgia, Kentucky, Maryland, North Carolina, South Carolina, Tennessee, Virginia, and West Virginia.1 The guild collections include the Robert W. Gray library, the permanent artifact collection, and the archives. The library serves to "collect, preserve, and make available for research materials concerning the appreciation and knowledge of traditional and contemporary crafts, with particular emphasis on the craft heritage of the southern Appalachian region.”2 The permanent collection is comprised primarily of craft objects, such as pottery, weavings, woodwork, and dolls; a small portion of this collection is kept on display in a gallery that adjoins the library. The archives document the guild through historical records, personal papers, photographs, and other materials.3

\section{Facilities}

The guild has resided in its current location at the Folk Art Center since 1980, and the facilities bring together contemporary and historical crafting and regional culture in an information-rich environment. History is juxtaposed with modern context, as supported by contemporary and historical library materials, exhibitions, craft demonstrations, outreach activities, and sales of pieces by guild members. The library, archives, and galleries are located on the second floor of the building. Before ascending upstairs, visitors are first greeted by the downstairs information and attractions, which include the daily craft demonstrations in the lobby, the wares of Allanstand Craft Shop, and the Blue Ridge Parkway information desk. Recent craft demonstrations have included weaving, jewelry, cornshuck doll-making, pottery, and flutemaking. The gently sloping, open ramp to the second floor allows visitors a bird's-eye view of the craft shop, as well as a chance to catch glimpses of the gallery items on display upstairs. 
On the second floor, visitors pass through the galleries to reach the library, situated in a quiet corner just past the gallery receptionist's desk. Visitors to the library can consult both historical and contemporary resources that are held within the greater context of the Folk Art Center galleries and which display items from the guild's permanent collection, as well as rotating exhibits with various features. The Focus Gallery generally features work from one or two artisans, while the Main Gallery primarily features group exhibitions. Recent exhibitions have featured works by Southern Highland Craft Guild members, works from the Department of Visual Arts at North Georgia College and State University, works by graduate students from Haywood Community College's Professional Crafts Department, and items from the Asheville Quilt Guild.

\section{Staffing and Services}

The library and archives are staffed by Deborah Schillo, the guild's first full-time librarian and archivist. The gallery receptionist can field general questions at the public service desk between the gallery and the library, but research questions regarding the collection are directed to Schillo. In addition to research and reference, Schillo manages all library and archives functions, including serials management, acquisitions, and cataloging.

The library is open to the public with the same schedule as the Folk Art Center, which is open every day of the year except Thanksgiving, Christmas, and New Year's Day. The archives are also available for public use, though appointments are required. Patrons are primarily craftspeople and frequently include members of local crafting groups, such as the Carolina Mountain Woodturners and the Asheville Quilt Guild, which hold regular meetings at the Folk Art Center. According to Schillo, library use is primarily academic. When asked about notable patrons over the years, Schillo mentioned Georgia Bonesteel, a well-known quilter of the PBS television series "Lap Quilting with Georgia Bonesteel." Not only has Bonesteel consulted the library's quilting resources over the years, but she has donated some of her own books to the collection.

\section{Collection Focus and Formats}

The library serves as a resource for crafters and non-crafters alike. The collections should appeal to researchers interested in the region, in craft history, and craft techniques, as well as those looking for information on some specific artisans, many of whom are documented in the archives of the guild. The library collection, which has been growing since the 1930s, has been built primarily through donations, and is supplemented by the library's modest budget. The collection 
now includes more than 10,000 books and 150 periodical titles, though only forty-eight of these serials are current titles. The primary focus of the collection is craft-related materials, with local and regional history materials, such as Appalachian and Cherokee studies, as a secondary priority. Another area of significant representation, grown through donations, is Asian art and traditions. Craft-related titles range from historical background information to how-to guides, and formats include books, serials, DVDs, videos, audio recordings, pamphlets, and ephemera.

According to Schillo, quilting and weaving are the two craft areas with the strongest representation within the collection. Other arts and crafts documented in the collection include architecture, basketry, beading, calligraphy, doll-making, enameling, furniture-making, glass, jewelry, knitting and crochet, metalwork, needlepoint, paper and fiber crafts, photography, pottery, printmaking, sculpture, textiles, and wood crafts, such as wood-carving and woodturning. Titles are both historical and contemporary, and associated information, such as crafting health hazards, are also included in the collection. The library collection includes many unique or rare materials, such as historic weaving sample books. These sample books include actual woven pieces that demonstrate various patterns, so that weavers can see physical, woven examples of what finished patterns look like.

The archives, which currently stand at approximately 300 linear feet, serve to document guild history through organizational records, personal papers, artist profiles, photographs, audio-visual items, and other materials. For much of the guild's history, the archival materials lacked professional organization that would allow patrons to access and use the items. Recent years brought grant funding for professional archival processing, and now the archival collections are available for use by appointment. One notable collection within the archives is the Doris Ulmann photograph collection. Portrait photographer Ulmann traveled through the Appalachian region during the late 1920s and early 1930s, and documented many artisans and craftspeople along the way.4

Serials, Acquisitions, and Cataloging

The library's online catalog is available for searching only within the library, though Schillo also maintains a library presence on the Web site LibraryThing.5 Online catalog access is one area where Schillo would like to see the library expand in the future. She catalogs items using the Decimal System. When selecting items, requests are given weight, and Schillo balances requests with relevant periodicals for suggestions of items to consider for the collection. About half of the yearly budget is spent on serials subscriptions, and all current serials are print publications. Serials are currently checked in using Gaylord's paper check-in cards. Schillo stated that they 
could do this on the computer, but the paper system is easier at this time. The guild subscribes to forty-eight current periodicals. Serial titles cover general crafting interests as well as specialty, niche publications and include American Craft, Handwoven, Ceramics Monthly, Fine

Woodworking, Studio Potter, Sunshine Artist, and Surface Design. The guild has been subject to serials cancellation projects during tight budget times, but has been fortunate in being able to fill in some titles through donated materials. Donations have helped the guild collections grow significantly over the years, as some members and friends choose to donate personal collections of books and papers. Schillo recalled one particularly special gift from a local music teacher, who donated a collection of books on rugs and design, some dating back to the nineteenth century, including rare folio editions. The library's association with local crafting guilds has also benefited the collection, with the library now housing the Asheville Quilt Guild library, as well as part of the Western North Carolina Handweavers Guild collection.

\section{Digital Collections}

While the library and archives do have Web sites through the Southern Highland Craft Guild Web page,6 most of their content is available for use only in the physical building. Circulation of library items was discontinued in the 1990s after a collection inventory showed that a number of books and other materials had disappeared from the shelves. While library items are noncirculating, the archives of the guild are part of a digitization project as one of the seven partners in the Craft Revival Project.7 This online initiative, operating out of Western Carolina University's Hunter Library, documents the historic revival of handicrafts in the southern Appalachian region in the late nineteenth century and early twentieth century.8 The Web site and its collections provide historical context as well as interpretive material. The collections document the artisans of the Craft Revival era artisans and their crafts through digitized documents, photographs, and objects. With significant relevant collection holdings, the guild has been the largest contributor to the project thus far. At the time of this writing, the guild had contributed nearly 2,000 items to the Craft Revival database. Schillo says that the Craft Revival Web presence has served to introduce some researchers to the guild and its collections by bringing them into the library and archives.

\section{Current Initiatives and Future Planning}

Raising awareness and use of the collection is a priority, as is collection expansion. The guild continues to expand its collections through purchases and donations. Schillo is building up the book collection by adding second copies of items whenever possible, with the hope that the library can start circulating second copies in the future. Patrons have requested the reinstatement of circulation services, and second-copy circulation would address this, while also hopefully bringing more patrons into the library. Beyond second-copy expansion, Schillo would like to 
consider adding some periodicals on CD, as well as additional multimedia materials such as videos of artisans demonstrating their crafts. Expansion of the library's physical space is also a desire for the future.

\section{Conclusion}

The Southern Highland Craft Guild was born out of the cooperative spirit of Appalachian artisans, and that spirit still thrives today. This unique organization is immersed in and connected to the history and roots of the geographic area, while supporting and furthering the work of artisans today. The guild collections and the greater Folk Art Center inform and educate visitors through this blending of historical and contemporary resources and experiences, and remind visitors of the importance of the creative spirit.

\section{Notes}

Southern Highland Craft Guild, "Folk Art Center: General Info,” http://www.southernhighlandguild.org/pages/folk-art-center/general-info.php (accessed January 13, 2011).

2. Southern Highland Craft Guild, "Robert W. Gray Library Collection," http://www.southernhighlandguild.org/pages/resources/robert-w.-gray-library-collection.php (accessed January 13, 2011).

3. Craft Revival: Shaping Western North Carolina Past and Present, “The Collection: Southern Highland Craft Guild,” http://www.wcu.edu/craftrevival/collection/southern_highland_craft_guild.html (accessed January 13, 2011).

4. Ibid.

5. LibraryThing: Southern Highland Craft Guild, "Profile," http://www.librarything.com/profile/SHCG (accessed January 18, 2011).

6. Southern Highland Craft Guild, "Southern Highland Craft Guild,” http://www.southernhighlandguild.org/ (accessed January 18, 2011).

7. Craft Revival: Shaping Western North Carolina Past and Present, “The Collection,” http://www.wcu.edu/craftrevival/collection/index.html (accessed January 18, 2011).

8. Craft Revival: Shaping Western North Carolina Past and Present, “The Story,” http://www.wcu.edu/craftrevival/story/index.html (accessed January 13, 2011). 